\title{
Implementation of gestational weight gain guidelines - what's more effective for ensuring weight recording in pregnancy?
}

\author{
Shelley Wilkinson ${ }^{1,2,3^{*}}$, Michael Beckmann ${ }^{2,3}$, Elin Donaldson ${ }^{1,3}$ and Sally McCray ${ }^{1,2}$
}

\begin{abstract}
Background: Pregnant women who gain weight in accordance with guidelines have the lowest risk of pregnancy and birth-related complications. However, evidence-practice gaps often exist. To address pregnancy weight management barriers, a stepped implementation science approach was used, comprising targeted in-services, provision of scales for clinic rooms, and changes to routine weight recording in a hospital electronic medical record. The aim of this study was to assess the cumulative influence of evidence-based interventions on staff's compliance to recording of antenatal weights.

Methods: Retrospective data analysis of weight recording over three 15-month cohorts across April 2014-December 2017. Variables calculated from data included: proportion of women with weight recorded at booking and proportion of women who had a weight recorded at each visit. Generalised estimating equation modelling was used to examine differences in weight recording compliance rates between cohorts, pre-pregnancy body mass index categories, model of care and clinicians.
\end{abstract}

Results: There were approximately 13,000 pregnancies in each cohort. The proportion of women who had a weight recorded at each visit per cohort differed significantly between cohorts from 4.2\% (baseline), 18.9\% (scales and in-services) to 61.8\% (medical record prompts), $p<0.001$.

Conclusion: Significant improvements were achieved through systematic barrier analysis and subsequent mapping and implementation of appropriate and effective interventions. Improvements were observed across the entire service, in all models of care with all professional groups demonstrating increased recording of weights.

Keywords: Antenatal, Weight recording, Guidelines, Implementation, Translation

\section{Introduction}

Pregnant women who gain weight in accordance with the US Institute of Medicine (IOM) guidelines, also adopted for use in Australia [1-4], have the lowest risk of pregnancy and birth-related complications. Their infants are also at reduced risk of incurring a chronic disease during their adult lives [1]. However, existing service processes and delivery of care does not always support women to adhere to best practice guidelines and

\footnotetext{
* Correspondence: Shelley.wilkinson@mater.org.au

${ }^{1}$ Department of Dietetics and Foodservices, Mater Health, Brisbane,

Queensland 4101, Australia

${ }^{2}$ Mater Research Institute - University of Queensland, Mothers, Babies and

Women's Theme, Brisbane 4101, Australia

Full list of author information is available at the end of the article
}

achieve these outcomes. Even when good evidence is available to support maternal behavioural change, health professionals do not necessarily adopt it, or disseminate it to women [5-8]. This is a broader problem in healthcare delivery, also recognised in many acute care settings [9-11].

A recent systematic review and meta-analysis noted that weighing as a stand-alone intervention does not reduce excessive gestational weight gain (GWG) [12]. However, it has been clearly demonstrated that interventions that include dietary advice, and physical activity, supported by ongoing weight monitoring, can prevent excessive GWG and result in more women across all body mass index (BMI) categories achieving weight gain

(C) The Author(s). 2019 Open Access This article is distributed under the terms of the Creative Commons Attribution 4.0 International License (http://creativecommons.org/licenses/by/4.0/), which permits unrestricted use, distribution, and 
within the correct ranges [13]. This approach has been shown to be highly efficacious when delivered by obstetricians and midwives and supported by dietitians, in an antenatal setting [14]. Further, many clinical guidelines (e.g. IOM, Queensland Health [1, 15]) rely on accurate weight records for timely clinical interventions, such as referral to anaesthetists and dietitians and for undergoing glucose tolerance testing.

Simply producing and disseminating guidelines does not always effect practice change. Evidence-practice gaps may continue to exist [16] and to close this gap a systematic and theory-driven process (i.e. the implementation science methodology) is essential. This requires an assessment of influencing factors (barriers/enablers) and an implementation and evaluation plan that uses strategies to overcome and address barriers [17]. The use of a framework to underpin the process is highly recommended [18].

To address the management of the GWG evidencepractice gap at our tertiary maternity service we took a system-wide approach, using the theoretical domains framework (TDF) [17] to classify barriers, and used the behaviour change wheel (BCW) [19], articulating with the TDF, to design effective interventions. Barriers to guideline adherence were informed by serial surveys in 2011 [5] and 2014 [6] and included gaps in GWG knowledge (goals per BMI category, BMI cut-offs), inconsistent weighing and monitoring and recording practices, and staff confidence in their own capabilities to counsel women who were overweight, obese, and/or experiencing excessive GWG. These barriers were classified in the TDF domains of: Knowledge, Skills, Social and Professional Role/Identity, Beliefs about capabilities, and Environmental context and resources [5].

Interventions introduced following the 2011 survey to overcome the identified barriers were delivered within existing resources and aimed to increase capacity and support within clinic. This was operationalised as increased dietetic time in the antenatal clinic comprising group and individual appointments, and delivery and follow up of the 'Healthy Start to Pregnancy' initiative (an evidence-based behaviour change workshop) [20] (to address the barrier of Environmental context and resources and to address the extra support required beyond staff's perceived capabilities). In addition, all women were given a 'Mater Personalised Pregnancy Weight Tracker' ('Weight Tracker') developed in-house by the maternity hospital dietitians [21] with associated staff training in its use around GWG. This addressed the barriers of Knowledge, Skills and staff's confidence in their capabilities.

Following the 2014 survey, compliance with individual elements of the guideline recommendations improved, such as improved (accurate) documentation of pre-pregnancy
BMI and discussing and correctly advising women about GWG goals, however overall guideline adherence did not improve [6]. Subsequent interventions related to identified gaps were implemented in stages including:

a) Obtaining scales for each antenatal clinic room (2014),

b) staff in-services training outlining and incorporating the evidence in to practice via voice over PowerPoint presentation (2014), and.

c) removal of default 'skip' option from the electronic record weight recording to promote mandatory recording (September 2016).

These addressed the TDF barrier domains of knowledge (through enablement/modelling), skills (through training), professional and social role/identify (through education/environmental restructuring) and environmental context and resources (through environmental restructuring).

The aim of this study was to assess the cumulative influence of these interventions on staff's compliance to recording of antenatal weights.

\section{Methods \\ Design and participants}

This retrospective study analysed data recorded by midwifery and obstetric clinicians from all models of care within the publically-funded Mater Mothers Hospital (MMH) antenatal service, across three cohorts over three periods of 15 months. Cohort 1 measured baseline weighing practices (April 2014-June 2015), cohort 2 measured effect of the availability of scales on weighing practices (July2015-September2016), and cohort 3 measured effect of mandatory weight recording in Matrix (the hospital's electronic maternity data set: Meridian Health Informatics) on weighing practices (September 2016-December 2017). The models of care include the general and specialist antenatal clinics (e.g. pregnancy after loss; high risk; young women's clinics, indigenous clinics, refugee clinics; general practitioner clinics) as well as midwifery group practice and community midwifery clinics.

\section{Procedure and data analysis}

Data were extracted from Matrix in three 15 month time periods. The variables of interest were: 1 . Visit data (date of first visit; number of antenatal visits; whether weight was recorded at each visit; clinician type who recorded weight at visit; model of care (MOC) for each visit) and 2. anthropometric data (weight at booking; height; pre-pregnancy body mass index (ppBMI). Overall GWG was not able to be analysed due to the low numbers of recorded weight in cohorts 1 and 2 . 
Women's characteristics were summarised using frequencies and percentages for categorical variables and means (standard deviation (SD)) or medians (interquartile range (IQR)) for continuous variables. Associations between cohort and categorical variables were examined using a Pearson Chi-squared test. Differences in mean heights and median weight measurements were examined by ANOVA and Kruskal -Wallis tests, respectively. Generalised estimating equation logistic model was used to examine differences in weight recording compliance rates between cohorts by patient pre-pregnancy BMI categories, models of care or clinicians. The exchangeable working correlation structure and robust variance estimation were used to account for correlation between multiple visits within a patient. The level of statistical significance was set at 0.05 . Statistical analysis was performed using STATA 15.1.

\section{Ethical considerations}

Ethical approval was obtained from the hospital's Human Research Ethics Committee (HREC/14/MHS/ 119. Amendment AM01).

\section{Results}

There were approximately 13,000 pregnancies in each cohort (Table 1). Women's median pre-pregnancy weight was similar across each cohort $(p=0.10)$. The remaining anthropometric measures (height, median ppBMI, booking weight) and gestation weeks at booking were all statistically (but not clinically) significantly different (all $p<0.001)$.

Consistency of recording of booking weights differed significantly across cohorts $(p<0.001)$ (Table 2$)$. The proportion of women who had a weight recorded at each visit per cohort (overall) also differed significantly between cohorts 1,2 , and 3 from 4.2 to $18.9 \%$ to $61.8 \%$, $p<0.001$ (Table 2). This had a similar pattern across clinician groups, MOC, and ppBMI categories (all $p<0.001$ ). The compliance rates for weight recording (overall) in cohort 2 and cohort 3 were 4.54 (95\% CI 4.24-4.86) times and 15.0 (95\% CI 14.2-16.0) times as high as the compliance rate in cohort 1 , respectively. Overall, women with ppBMI categories $<18.5 \mathrm{~kg} / \mathrm{m}^{2}$ and $>30 \mathrm{~kg} / \mathrm{m}^{2}$ were more likely to have their weights at subsequent visits recorded (RR 1.10, 95\% CI 1.03-1.18 and RR 1.11, 95\% CI 1.061.17 , respectively) compared to those with a ppBMI 18.5$24.9 \mathrm{~kg} / \mathrm{m}^{2}$ (healthy BMI range).

\section{Discussion}

This study of consistency of routinely collected weight recordings clearly demonstrates the cumulative influence of targeted interventions on staff's adherence to recording of antenatal weights. These significant improvements were achieved through systematic barrier analysis and subsequent mapping and implementation of appropriate and effective interventions $[17,19]$. Improvements were observed across the entire service, in all MOC, with all professional groups demonstrating increased recording of weights. The cumulative changes positively influenced the recording of weight during women's pregnancies. More weights were recorded at a visit in each cohort for women in the underweight and obese BMI categories.

Under-recording of weights is a well-recognised issue in the acute healthcare setting despite its acknowledged importance on patient and clinical outcomes [10]. The low rate of weights recorded is similar to that seen in acute care hospital settings, with audits documenting 2, 18,22 and $28 \%$ of weights being recorded [10, 11], despite $80 \%$ of staff acknowledging its importance on patient/clinical outcomes [10]. Another Australian/New Zealand audit of nutrition care practices in hospital wards revealed only $32 \%$ of 370 wards surveyed documented weights, with $55 \%$ only recording it "when requested" [9]. In the broader health care arena, correct and timely documentation of weight is important for safe prescribing practices, manual handling, skin integrity management, and identifying nutritional risk [10]. The importance of clearly documented weights and therefore rate of GWG is similarly important in maternity care, informing anaesthetic care-planning, allowing detection of potential metabolic complications (GDM), determining resource requirements (beds, blood pressure cuffs, ultrasound processes), and as an indicator of nutritional risk.

Fealy et al's systematic review and meta-analysis did not find routine weighing reduced excessive GWG [12].

Table 1 Women's anthropometry and pregnancy details across the 3 study cohorts

\begin{tabular}{lllll}
\hline & $\begin{array}{l}\text { Cohort 1 } \\
\text { (n women =13,577) }\end{array}$ & $\begin{array}{l}\text { Cohort 2 } \\
(n=13,481)\end{array}$ & $\begin{array}{l}\text { Cohort 3 } \\
(n=12,861)\end{array}$ \\
\hline Date range (months) & April 2014-June 2015 (15) July 2015-September 2016 (15) & October 2016-December 2017 (15) \\
pp weight (kg), median (IQR) & $63.0(56.0-72.0)$ & $63.0(55.0-73.0)$ & $63.0(55.0-73.0)$ & 0.10 \\
Weight at booking (kg), median (IQR) & $70.0(62.0-80.0)$ & $68.0(60.0-79.0)$ & $69.0(61.0-79.3)$ & $23.1(20.7-26.8)$ \\
ppBMl, median (IQR) & $22.7(20.4-25.9)$ & $22.9(20.5-26.5)$ & $20.0(14.6-22.6)$ & $<0.001$ \\
Gestation at booking (weeks), median (IQR) & $21.5(15.2-29.4)$ & $18.3(14.6-21.3)$ & $<.001$
\end{tabular}

Data are presented as $\%(\mathrm{n} / \mathrm{N})$ for categorical variables. IQR interquartile range, $p p$ pre-pregnancy, $B M I$ body mass index 
Table 2 Service use and weight recording practices across the 3 study cohorts

\begin{tabular}{|c|c|c|c|c|}
\hline & $\begin{array}{l}\text { Cohort } 1 \\
\text { ( } n \text { visits }=38,785)\end{array}$ & $\begin{array}{l}\text { Cohort } 2 \\
(n=32,694)\end{array}$ & $\begin{array}{l}\text { Cohort } 3 \\
(n=24,623)\end{array}$ & $p$-value \\
\hline Date range (months) & April 2014-June 2015 (15) & July 2015-September 2016 (15) & October 2016-December 2017 (15) & \\
\hline $\begin{array}{l}\text { Proportion of women with weight each } \\
\text { visit recorded (overall) (\%) }\end{array}$ & $4.2 \%$ & $18.9 \%$ & $61.8 \%$ & $<0.001$ \\
\hline Weight recorded at booking visit & $92.2 \%$ & $84.8 \%$ & $92.2 \%$ & $<0.001$ \\
\hline $\begin{array}{l}\text { Proportion of women with weight each } \\
\text { visit recorded (\%) - By clinician group }\end{array}$ & & & & $<0.001$ \\
\hline by Midwives & $4.0 \%$ & $20.7 \%$ & $62.5 \%$ & \\
\hline by Doctors & $4.1 \%$ & $7.6 \%$ & $53.3 \%$ & \\
\hline By model of care & & & & $<0.001$ \\
\hline In the hospital & $4.0 \%$ & $15.7 \%$ & $56.6 \%$ & $<0.001$ \\
\hline In the community & $4.0 \%$ & $24.7 \%$ & $69.8 \%$ & $<0.001$ \\
\hline By ppBMl category & & & & $<0.001$ \\
\hline$<18.5 \mathrm{~kg} / \mathrm{m}^{2}$ & $5.7 \%$ & $22.0 \%$ & $64.6 \%$ & $<0.001$ \\
\hline $18.5-24.9 \mathrm{~kg} / \mathrm{m}^{2}$ & $3.8 \%$ & $17.3 \%$ & $60.9 \%$ & $<0.001$ \\
\hline $25-29.9 \mathrm{~kg} / \mathrm{m}^{2}$ & $3.6 \%$ & $20.0 \%$ & $62.0 \%$ & $<0.001$ \\
\hline $30+\mathrm{kg} / \mathrm{m}^{2}$ & $5.8 \%$ & $21.5 \%$ & $63.5 \%$ & $<0.001$ \\
\hline
\end{tabular}

However, the two included studies did not incorporate any dietary, physical activity, or behavioural change interventions known and shown to be required for effective healthy weight management during pregnancy [13, 22]. The authors opined that routine weighing is as important as blood pressure measurement [12]. Routine weighing is acceptable to women and has not been shown to increase anxiety or distress [23]. It is also a valuable opportunity to act and counsel women to support a healthy pregnancy and can assist clinicians providing appropriate and timely interventions [24].

Despite the absence of data to compare GWG across the three cohorts, we are able to draw on self-reported data from a smaller population from the same study period to provide a proxy measure of the interventions' effectiveness [25]. In this paper examining women's service engagement, health behaviours and GWG across 2014-17 (n421) with a cohort of women surveyed at the opening of the $\mathrm{MMH}$ in 2008 (n102) we were able to demonstrate that the proportion of women experiencing correct GWG increased from 23.2 to $38.6 \%$ (with excessive GWG decreasing from 57.3 to $32.6 \%$ ), $p<0.001$ [25]. We noted the significant increase in women gaining weight within the recommended IOM guideline ranges was a very promising outcome which was lower than many recent studies that used similar methodologies (E.g. 38\% [26], 39\% [27], 42\% [28], 47\% [4], and 52\% [29]). Furthermore, we demonstrated that a greater proportion of women accessed the nutrition services in 2014-17 compared with 2008 (19.7\% vs 9.9\%) and rated nutrition resources provided and/or viewed favourably (> 3.5 out of 5 ) [25].

Simple system changes appear to be most effective for sustainable outcomes in this instance of antenatal weight recording. It has been noted that reliance on memory less consistently elicits behaviour change compared to routine structural changes [30]. Thus, when scales were available, the removal of a default skip in the weight recording process became an 'electronic reminder'. These interventions elicited greater improvements than have previously been documented for reminder systems (usually only $\sim 4 \%$ ) [31], perhaps through being uniquely tailored to the local barriers in place. A recent review of eHealth technologies in hospital practice presented strong evidence that electronic medical records can substantially increase clinician adherence to guidelines and accuracy and completeness of clinical information, especially when used at the point of care and integrated into workflows [32].

This study's strengths were its large sample size, extended period of measurement, and the use of the implementation science approach to devise effective strategies to overcome known barriers to the practice of consistent regular weighing of women. Limitations relate to the inability to determine the effect of the increased weight recording on GWG and the resultant effects on clinical outcomes such as shoulder dystocia, induction of labour, operative delivery, and neonatal hypoglycaemia. Furthermore, due to the relatively late timing of the women's booking visit there is the potential for inaccuracies of pre-pregnancy weight reporting. However, it has 
been demonstrated that there is a high correlation between measured and self-report anthropometry [33]. There is also the potential for an unhealthy weight gain trajectory to be established with later bookings which should be addressed in future interventions.

Additionally, we do not know how the experience of weighing affected women, or the clinicians delivering care, and if this impacted referral practices. However, the serial improvements reflect that the practice of weight recording increased across all models of care which is likely to have had positive effect on women's care overall. Other studies have documented that women like and expect to be weighed if it is performed in a respectful manner [23, 34]. Although some staff report feeling anxious about weighing women [35-37] we are providing additional training and support to help them overcome this barrier. This may also address the less than $100 \%$ compliance rate for weight recording.

To enable monitoring of practices against guidelines, including rate of and overall GWG, we will investigate the possibility of modifying the dataset to easily capture (and extract) weight at K28 and K36. This will also allow linking routine monitoring of GWG to pregnancy outcomes. We will also investigate the possibility of incorporating the paper Mater Personalised Pregnancy Weight Tracker [21] into the electronic record. This operationalizes a very effective behaviour change intervention, audit and feedback $[38,39]$, by providing real-time data on a woman's progress and prompting staff on the required actions for when a woman deviates from her recommended weight trajectory.

\section{Conclusion}

In our recent paper presenting service-wide changes to support healthy GWG, we noted that the effectiveness of changes can be difficult to tease apart when a suite of changes are implemented concurrently [6]. Using a stepped approach we have been able to demonstrate the cumulative effectiveness of evidence-based interventions targeted to known barriers [38] and have reinforced the knowledge that interventions based on environmental restructuring, restriction (of processes or practices), enablement, incentivisation and/or coercion can be more effective than relying on an individual's choice to facilitate the "automatic" delivery of best practice [21].

\footnotetext{
Abbreviations

ANOVA: Analysis of variance; BCW: Behaviour change wheel; BMI: Body mass index; GDM: Gestational diabetes mellitus; GWG: Gestational weight gain; HREC: Human research ethics committee; IOM: Institute of Medicine; IQR: Interquartile range; MMH: Mater Mothers Hospital; MOC: Model of care; ppBMI: Pre-pregnancy BMI; SD: Standard deviation; TDF: Theoretical domains framework
}

\section{Acknowledgements}

Thanks to Satomi Okano, Statistician, Queensland Institute of Medical Research, for her assistance with data analysis.

\section{Funding}

Dr. Shelley Wilkinson is supported by a Queensland Government Health Research Fellowship.

\section{Availability of data and materials}

The datasets generated and/or analysed during the current study are not publicly available due to being generated from a hospital's clinical database but are available from the corresponding author on reasonable request.

\section{Authors' contributions}

All authors have participated sufficiently in the article to take public responsibility for the content. SW (corresponding author) was involved in the planning of this project, the analysis, and interpretation of data, and the writing of the paper. SMc, MB, and ED assisted in the planning of the project, interpretation of the data and the writing of the manuscript. All authors read and approved the final manuscript.

\section{Ethics approval and consent to participate}

Consent was not required from patients. This project methodology was assessed to meet the requirements of the National Statement on Ethical Conduct in Human Research (2007) and ethical approval was obtained from the Mater Health Services Human Research Ethics Committee (HREC/14/ $\mathrm{MHS}$ 119. Amendment AM01)

\section{Consent for publication}

Not applicable.

\section{Competing interests}

The authors declare that they have no competing interests.

\section{Publisher's Note}

Springer Nature remains neutral with regard to jurisdictional claims in published maps and institutional affiliations.

\section{Author details}

'Department of Dietetics and Foodservices, Mater Health, Brisbane, Queensland 4101, Australia. ${ }^{2}$ Mater Research Institute - University of

Queensland, Mothers, Babies and Women's Theme, Brisbane 4101, Australia.

${ }^{3}$ Mater Mothers' Hospitals, Mater Health, Brisbane 4101, Australia.

Received: 9 April 2018 Accepted: 21 December 2018

Published online: 12 February 2019

References

1. Institute of Medicine. Weight gain during pregnancy: reexamining the guidelines. Washington, D.C.: The National Academies Press; 2009.

2. NHMRC. Australian Dietary Guidelines: Eat for Health. Canberra: National Health and Medical Research Council; 2013.

3. The Royal Australian and New Zealand College of Obstetricians and Gynaecologists: Management of obesity in pregnancy. In. Edited by RANZCOG. Melbourne; 2013.

4. Goldstein RF, Abell SK, Ranasinha S, Misso M, Boyle JA, Black MH, Li N, Hu G, Corrado F, Rode L, et al. Association of Gestational Weight Gain with Maternal and Infant Outcomes: a systematic review and meta-analysis. JAMA. 2017:317(21):2207-25.

5. Wilkinson S, Stapleton H. Overweight and obesity in pregnancy: the evidence-practice gap in staff knowledge, attitudes and practices. Aus N Z J Obstet Gynaecol. 2012;52:588-92.

6. Wilkinson SA, Donaldson E, Beckmann M, Stapleton H. Service-wide management of healthy gestational weight gain following an implementation science approach. Maternal and Child Nutrition. 2016 https://doi.org/10.1111/mcn.12266.

7. de Jersey SJ, Nicholson JM, Callaway LK, Daniels LA. An observational study of nutrition and physical activity behaviours, knowledge, and advice in pregnancy. BMC Pregnancy Childbirth. 2013;13:115.

8. Hector D, Hebden L: Prevention of excessive gestational weight gain: an evidence review to inform policy and practice. In. Edited by Group PANOR; 2013.

9. Agarwal E, Maree F, Banks M, Batterham M, Bauer J, Capra S, Isenring E. Nutrition care practices in hospital wards: results from the nutrition care day survey 2010. Clin Nutr. 2012;31:995-1001. 
10. Evans A. Positive patient outcomes in acute care: does obtaining and recording accurate weight make a difference? Aust J Adv Nurs. 2012;29(3):62-7.

11. Hilmer S, Rangiah C, Bajorek B, Shenfield G. Failure to weigh patients in hospital: a medication safety risk. Intern Med J. 2007;37:647-50.

12. Fealy SM, Taylor RM, Foureur M, Attia J, Ebert L, Bisquera A, Hure A. Weighing as a stand-alone intervention does not reduce excessive gestational weight gain compared to routine antenatal care: a systematic review and meta-analysis of randomsied controlled trials. BMC Pregnancy Childbirth. 2017;17:36.

13. Amorim A, Linne Y: Diet or exercise, or both, for weight reduction in women after childbirth Cochrane Database of Systwematic Reviews 2013, 23 (7):CD005627. doi: 005610.001002/14651858.CD14005627.pub14651853.

14. Yeo S, Walker J, Caughey M, Ferraro A, Asafu-Adjei JK. What characteristics of nutrition and physical activity interventions are key to effectively reducing weight gain in obese or overweight pregnant women? A systematic review and meta-analysis. Obes Rev. 2017;18(4):385-99.

15. Obesity (Statewide Maternity and Neonatal Clinical Guideline) [https://www. health.qld.gov.au/__data/assets/pdf_file/0019/142309/g-obesity.pdf].

16. Grol R, Wensing M. What drives change? Barriers to and incentives for achieving evidence-based practice. Med J Aust. 2004;180(6):S57-60.

17. French SD, Green SE, O'Connor DA, McKenzie JE, Francis JJ, Michie S, Buchbinder R, Schattner P, Spike N, Grimshaw J. Developing theoryinformed behaviour change interventions to implement evidence into practice: a systematic approach using the theoretical domains framework. Implement Sci. 2012;7:38

18. Francis JJ, O'Connor D, Curran J. Theories of behaviour change synthesised into a set of theoretical groupings: introducing a thematic series on the theoretical domains framework. Implement Sci. 2012;7:35.

19. Michie S, van Stralen MM, West R. The behaviour change wheel: a new method for characterising and designing behaviour change interventions. Implement Sci. 2011;6:42.

20. Wilkinson S, McIntyre $\mathrm{H}$. Evaluation of the healthy start to pregnancy early antenatal health promotion workshop: a randomized controlled trial. BMC Pregnancy Childbirth. 2012;12:131

21. The Mater Personalised Pregnancy Weight Tracker (c): an evidence-based resource that takes the guesswork out of healthy pregnancy weight gain [http://wellness.mater.org.au/Our-Services/Nutrition-and-Dietetics/ Outpatients/The-Mater-Personalised-Pregnancy-Weight-Tracker-\%C2\%A9].

22. Willcox J, Wilkinson S, Lappas M, Ball K, Crawford D, Mccarthy E, Fjeldsoe B, Whittaker R, Maddison R, Campbell K. A mobile health intervention promoting healthy gestational weight gain for women entering pregnancy at a high body mass index: the txt4two pilot randomised controlled trial. Br J Obstet Gynaecol. 2017. https://doi.org/10.1111/1471-0528.14552.

23. Brownfoot F, Davey M, Kornman L. Women's opinions on being weighed at routine antenatal visits. Br J Obstet Gynaecol. 2016;123(2):263-70.

24. Dimperio D, Frentzen $B$, Cruz A. Routine weighing during antenatal visits. $\mathrm{Br}$ Med J. 1992;304(6825):460.

25. Wilkinson S, Donaldson E, McCray S. Re-evaluating the nutritional awareness, knowledge and eating behaviours of women attending a tertiary maternity hospital following iterative service design. Nutr Diet. 2018; 75(4):372-80.

26. de Jersey SJ, Nicholson JM, Callaway LK, Daniels LA. A prospective study of pregnancy weight gain in Australian women. Aust N Z J Obstet Gynaecol. 2012;52:545-51.

27. Cruickshank A, Porteous H, Palmer M. Investigating antenatal nutrition education preferences in South-East Queensland, including Maori and Pasifika women. Women Birth. 2018;31(4):278-84.

28. Porteous $\mathrm{H}$, Palmer M, Wilkinson S. Informing maternity service development by surveying new mothers about preferences for nutrition education during their pregnancy in an area of social disadvantage. Women Birth. 2014;27(3):196-201.

29. de Jersey S, Ross L, Himstedt K, Mclntyre H, Callaway LK. Weight gain and nutritional intake in obese pregnant women: some clues for intervention. Nutr Diet. 2011;68(1):53-9.

30. Michie S. Implementation science: understanding behaviour change and maintenance. BMC Health Serv Res. 2014;14(Suppl 2):09.
31. Shojania K, Jennings A, Mayhew A, Ramsay C, Eccles M, Grimshaw J: The effects of on-screen, point of care computer reminders on processes and outcomes of care Cochrane Database Syst Rev 2009, Issue 3. Art. No.: CD001096. DOI: https://doi.org/10.1002/14651858.CD001096.pub2

32. Keasberry J, Scott I, Sullivan C, Staib A, Ashby R. Going digital: a narrative overview of the clinical and organisational impacts of eHealth technologies in hospital practice. Aust Health Rev. 2017;41(6):646-64.

33. Brunner Huber L. Validity of self-reported height and weight in women of reproductive age. Matern Child Health J. 2007;11(2):137-44.

34. Allen-Walker V, Mullaney L, Turner MJ, Woodside JV, Holmes VA, McCartney DM, McKinley MC. How do women feel about being weighed during pregnancy? A qualitative exploration of the opinions and experiences of postnatal women. Midwifery. 2017;49:95-101.

35. Wilkinson S, Poad D, Stapleton H. Maternal overweight and obesity. A survey of clinicians' characteristics and attitudes, and their responses to their pregnant clients. BMC Pregnancy Childbirth. 2013;13:117.

36. Hasted T, Stapleton H, Beckmann MM, Wilkinson SA. Clinician's attitudes to the introduction of routine weighing in pregnancy. J Pregnancy. 2016. https://doi.org/10.1155/2016/2049673.

37. Willcox J, Campbell K, van der Plight P, Hoban E, Pidd D, Wilkinson S. Excess gestational weight gain: an exploration of Midwives' views, attitudes and practice. BMC Pregnancy Childbirth. 2012;12:102

38. Colquhoun H, Leeman J, Michie S, Lokker C, Bragge P, Hempel S, McKibbon KA, Peters G-J, Stevens KR, Wilson MG, et al. Towards a common terminology: a simplified framework of interventions to promote and integrate evidence into health practices, systems and policies. Implementation Science. 2014;9:51.

39. Ivers N, Jamtvedt G, Flottorp S, Young J, Odgaard-Jensen J, French S, O'Brien M, Johansen M, Grimshaw J, Oxman A: Audit and feedback: effects on professional practice and healthcare outcomes. Cochrane Database Systematic Reviews 2012, 13 (6):CD000259. doi: 000210.001002/14651858. CD14000259.pub14651853.

\section{Ready to submit your research? Choose BMC and benefit from:}

- fast, convenient online submission

- thorough peer review by experienced researchers in your field

- rapid publication on acceptance

- support for research data, including large and complex data types

- gold Open Access which fosters wider collaboration and increased citations

- maximum visibility for your research: over $100 \mathrm{M}$ website views per year

At $\mathrm{BMC}$, research is always in progress.

Learn more biomedcentral.com/submission 